\title{
B-learning for Parents' Informal Learning: PARENTS project
}

\author{
María José Rodríguez Malmier, Manuel Gromaz Campos, José Manuel Abuín Mosquera \\ Supercomputing Centre of Galicia, Spain
}

\begin{abstract}
PARENTS project is an educational project financed by the European Commission in the framework of the Lifelong Learning Program (Grundtvig scheme), which involves seven European institutions. The Supercomputing Center of Galicia (CESGA) carries out the technological part of the project. PARENTS' project main goal is to tackle the problem of training parents of adolescents to provide their children adequate orientation about studies and future employment options. This article describes the process of this project, its main achievements so far, and its technological aspects.
\end{abstract}

\section{Introduction}

It is an undeniable fact that parents play a crucial role in planning their children's future professional career. Although researches into this issue have been conducted in the USA and Canada for 10 years, in Europe it is still a new subject matter. Parents' project started in 2007 and will finish by Dec. 2009, being a innovative attempt to cover this not so explored field in training. Technology enhanced learning is also explored in order to provide the most flexible and appropriate training to a diverse group of parents.

\section{Project aims}

Some of the project main goals are:

- To increase awareness of parents that they are an important cell in the chain of their children career making process.

- To broaden parents' knowledge in a handy way: how to help your own child in choosing their professional path

- Empower peer-parents consultation role in parents' education.

- To encourage constant cooperation in the field of professional orientation between personal counselors at schools and parents of pupils

- To reduce stress among young people that results from making a difficult decision concerning the choice of profession through positive and specialist participation of parents in this process

- To improve communication between children and their parents as a result of the joint participation in making crucial lifetime decisions

- To improve the effectiveness of the choice of profession made by young people as a result of acting in accordance with their own interests and abilities as well as correlating the future profession with the demands of the job market

\section{Project partners}

There are seven institutions that take part in this project from six European countries:

Table 1. Project partners

\begin{tabular}{|c|c|}
\hline swspiz & $\begin{array}{c}\text { Academy of } \\
\text { Management - } \\
\text { Coordinator (Poland) }\end{array}$ \\
\hline & $\begin{array}{c}\text { Association Baobab } \\
\text { (Spain) }\end{array}$ \\
\hline & $\begin{array}{c}\text { University of Oradea } \\
\text { (Romania) }\end{array}$ \\
\hline
\end{tabular}

\begin{tabular}{|c|c|}
\hline an & $\begin{array}{l}\text { Institute for education, } \\
\text { Ltd. (Slovakia) }\end{array}$ \\
\hline & $\begin{array}{c}\text { Supercomputing } \\
\text { Center of Galicia } \\
\text { (Spain) }\end{array}$ \\
\hline dieBerater & Die Berater (Austria) \\
\hline & $\begin{array}{l}\text { Training } 2000 \\
\text { (Italy) }\end{array}$ \\
\hline
\end{tabular}

\section{Target groups}

The target groups of this project are:

- Parents of young people who face the choice of making a decision concerning the direction of 
their occupational education.

- Young people facing the choice of occupational education.

- Personal counselors working in schools and school teachers who provide their pupils with personal counseling.

- Training companies: will receive a new training programmed for counselors and teachers which will enrich their training offer.

- Universities, which provide courses of career counseling.

- Academic researchers: increase of the number of research on parents' influence on career choices made by their children, examining whether education of parents in this area brings positive results.

\section{Final users}

One of the most important aims of this project is to conduct several pilot experiences where real training will be provided to parents and evaluate its effectiveness.

First of all, it was considered necessary to know this group of parents' training needs regarding vocational and professional fields.

\section{Parents’ needs}

In each country a focus group formed by ten fathers and mothers was formed.

First of all, we needed to identify these parents' needs in the field of the vocational or professional adviser for his sons. So, before starting the pilot experiences on training for parents, each partner carried out a survey with his focus group. This was later on summarized in a survey which pointed out their opinions on:

- Parents' will in helping children vocational choices.

- Parents' xperience in cooperation with career counselors

- Parents' opinion on their children expectations while choosing a career

- Parents' expectations on counselors assistance.

- Parents' opinion on responsibilities/ roles between child, parents, counselors, or other institutions.

- Parents' perception on skills needed to develop the career planning of their children

- Parents' opinion on the form and content of the planned project "products" (training, e-learning web site)

- Parents' commitment, in terms of learning time, in order to provide their children better assistance

- Parents' preferences regarding training support: face to face courses, virtual platform for peer groups, or e-learning material.

\section{Training for parents}

Once these parents' training needs were identified, the project developed face to face and online training contents in the field of vocational and professional field for the training sessions that would follow. Training was envisaged to provide new handy skills for parents. Theoretical knowledge was limited to cover the basics. Practical skills are expected to be acquired during interactive face to face workshops (role playing, psychological exercises, dramas etc.). Theoretical knowledge was provided to the participants as auxiliary materials available through the project's virtual environment. Training sessions consists of the following issues:

- How to get to know your own child: his/her talents; his/her interests; his/her hierarchy of values, his/her personality.

- How to help a child in making occupational decisions through education: setting aims in a proper way; constructing plans and their realization; coping with objectively and subjectively difficult situations. - How to make use of the determinants of family environment and its occupational genetic diagram when planning the career of a child

- How to establish contact with the child and facilitate mutual communication in the key moments in the course of making occupational decisions by him/her.

- Where to search for the necessary information: institutions, web pages, literature connected with this issue.

\section{Pilot courses}

In each of the six participant countries a pilot course for 10 parents was organized.

The content of the courses was first developed in English, and then, translated to all the languages of the consortium. Each pilot course consisted of 30 hours, following a blended-learning methodology. 10 hours were devoted to face to face training and 20 hours online training. To provide the online training part, the e-learning area of the Supercomputing Center of Galicia analyzed parents' choices and likes and designed and implemented a virtual environment for both trainers and parents.

\section{Platform for trainers and parents}

The virtual environment was initially based on an Open Source software named Joomla - Joomla is a Content Management System- which initially complied with the main needs identified, and it was adapted to comply with the training and information needs of the project. 
At the beginning, it was stated that the main environment should not be a standard learning management system, but a more flexible environment, that would mainly serve to host personalized information for parents, as well as communication tools and some sort of self-learning materials. The environment should also serve as a public website for other parents who might be interested in the project results and future participation, as well as a private environment that would require personalized access for those parents who participated in the pilots.

Being a multilingual project, it should also take this into account and provide the seven languages used in the project (English was included as well).

Figure 1. Public section of the virtual environment

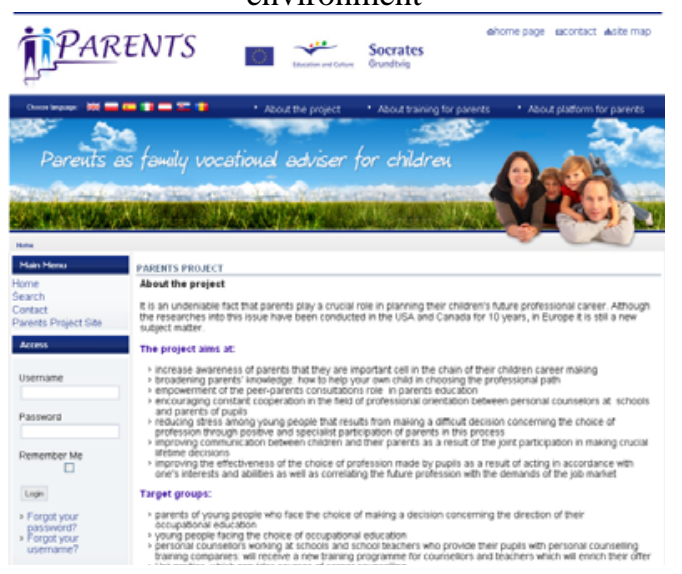

The private section counts on the following tools for trainers and parents:

a) Agenda Tool: In the agenda tool, trainers from different countries can add, modify or delete events about their local pilot courses.

Parents can check information in the agenda tool about the development of the pilot course.

Figure 2. Agenda tool

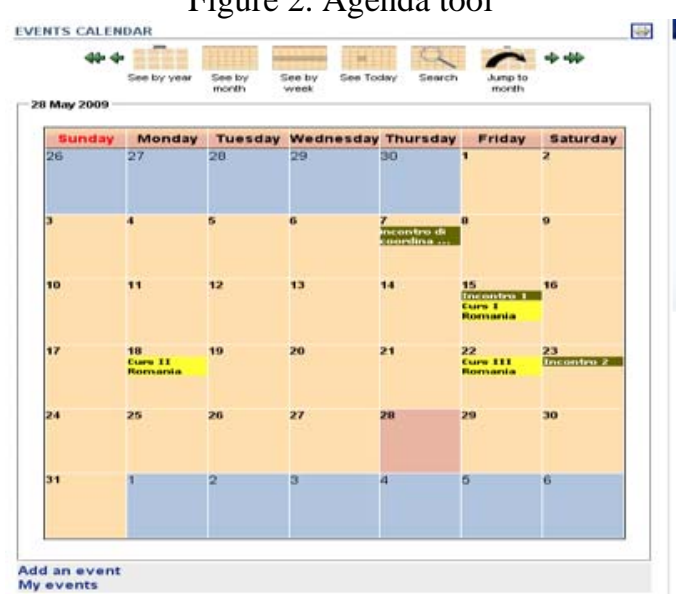

b) Forum tool.

The forum tool is used for sharing ideas among parents and also, among parents and trainers.

There is a main forum (in English) where parents and trainers from different countries can share ideas, and six forums (in Polish, Italian, Spanish, Romanian, German and Slovak) where parents and trainers from each country share ideas, exchange information etc.

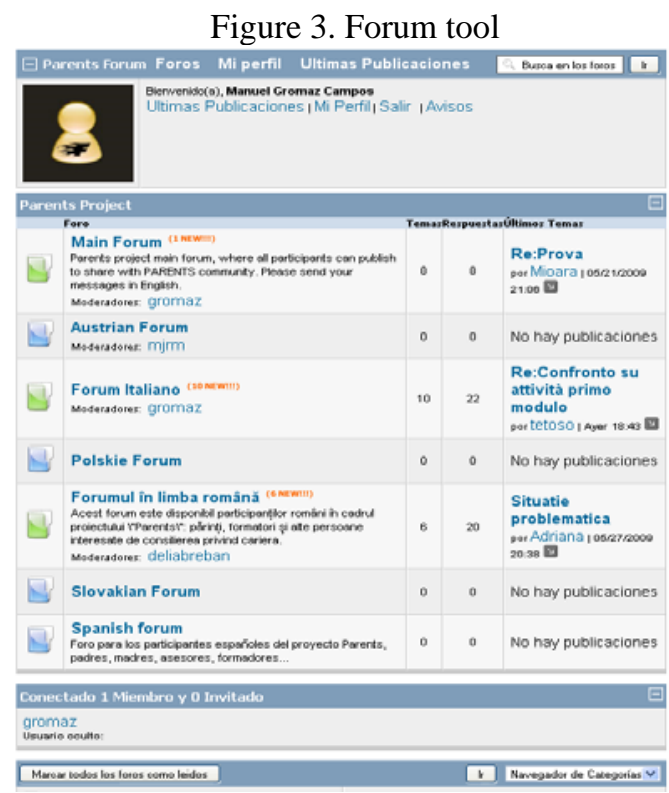

Trainers from each country, can create, moderate, edit or delete questions and answers, but only in the general forum and in their own language forum. For example, a trainer from Spain can only create, moderate, edit or delete questions and answers in the general forum or in the Spanish Forum.

In the same way, participant parents can only access the general and their own language forum.

c) Self study exercises.

The self study exercises are available for pupils (parents). This area has a theoretical section with activities and online forms.

Figure 4 Self study exercises.

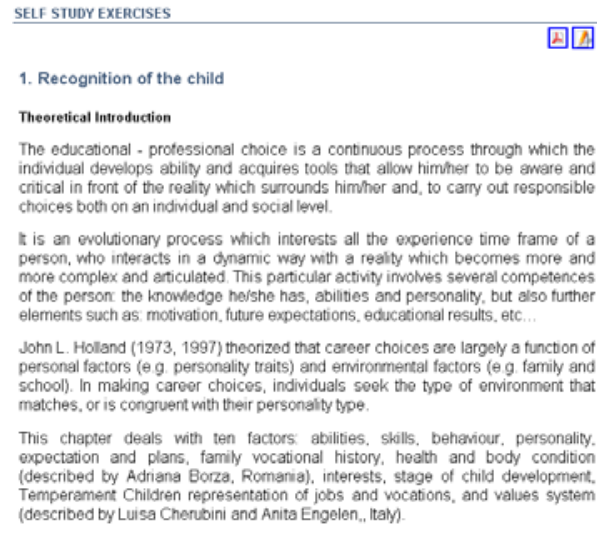


d) Case Study. The case studies are online exercises only available for participant parents.

This section has a brief introduction for each case and then self evaluated activities with online forms.

Figure 5. Case Study

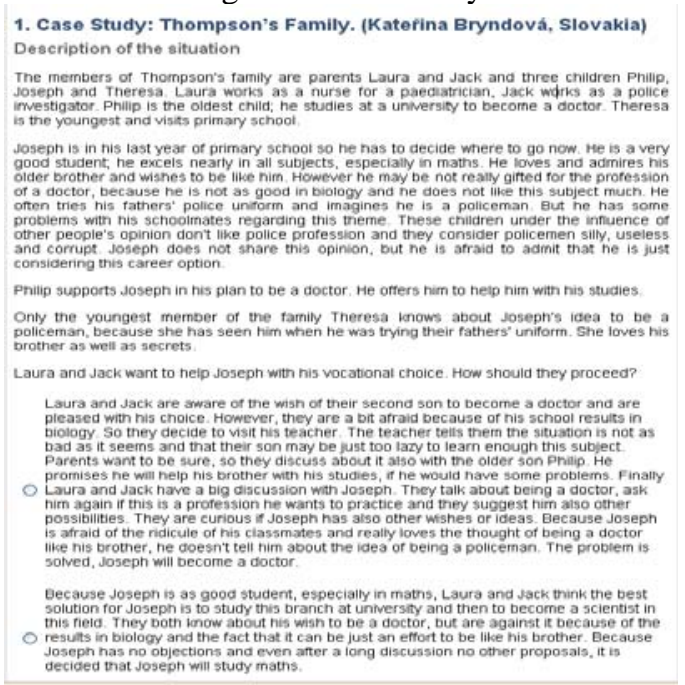

e) Recommended readings. In this category, there are two folders available for parents/trainers: one folder per country and a general one. The private folders are available for trainers, so, they can upload contents for the parents of their pilot course. And the common folder is available for all trainers that are taking part in this project to allow them upload materials for all groups in English language. So, parents can access the folder of their language for downloading documentation in their language and the general folder for downloading further information in English.

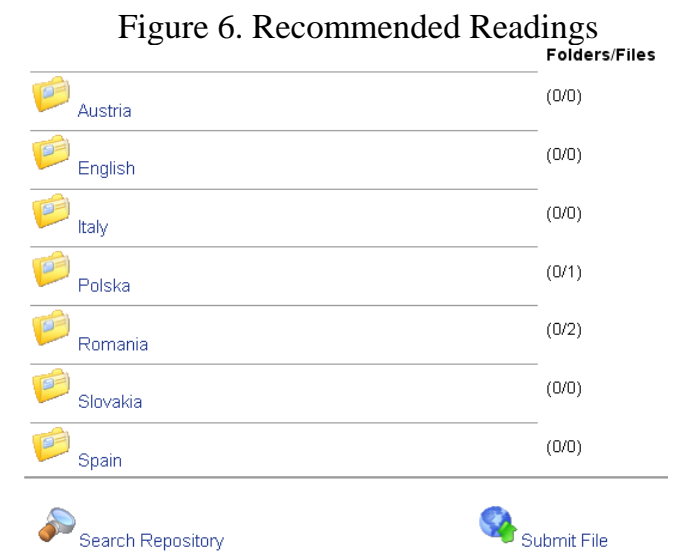

f) FAQ.

In the FAQ category, trainers have placed a collection of frequently answered questions for his pilot course users.

Figure 7. FAQs

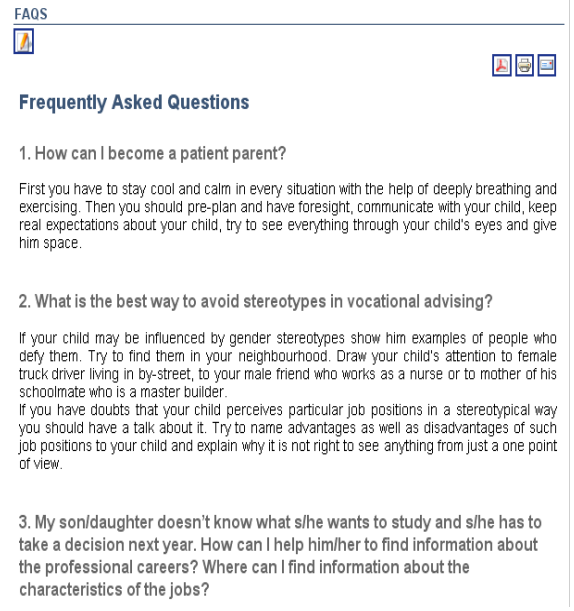

g) Search. With the search tool, parents and trainers can search anything contained in the virtual environment. They can search by keyword, free words, exact phrase, etc.

Figure 8. Search

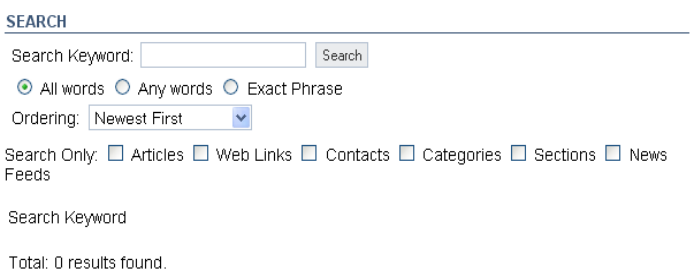

h) How to use the platform.

In this section trainers and parents can find tutorials that briefly describe the functionalities of the virtual platform. So, basic information such as how to register, how to the virtual platform works, etc. is shown here.

\section{i) Profile.}

In this section parents and trainers can edit their own details, so they can change their password and also select their preferred language to use in the platform.

Figure 9. Profile

\begin{tabular}{|c|c|}
\hline Username: & gromaz \\
\hline Your Name: & Manuel Gromaz Camp \\
\hline E-mail: & gromaz@cesga.es \\
\hline Password: & \\
\hline Verify Password: & \\
\hline Back-end Language: & Español (spanish fiv \\
\hline Front-end Language & Español (spanish fiv \\
\hline User Editor: & - Select Editor - $\quad$ \\
\hline Help Site: & Local \\
\hline Time Zone & (UTC +01:00) Amsi 2 \\
\hline Save & \\
\hline
\end{tabular}




\section{Products}

This project produced some useful products available once the project is finished. The most remarkable are 30-hour-long training for parents available on Cd-Rom together with methodical materials for the people who teach the course and materials for the participants of the course. A manual entitled "Parents as career counselors of their children. Training for parents" was produced as downloadable material by the participant counselors in the project. This manual covers the most relevant areas to be addressed when dealing with parents training in this issue. It provides a good source of information to build a good contact between counselors and parents, to motivate parents to act, set up goals, develop skills and personal character traits facilitating the analysis of one's career in such a way as to help the children in making good educational and vocational choices. It contains a detailed description of more than 30 practical classes, which can be used for work with parents of adolescents. The book has been divided into three parts. The first one - „How to work with a group of parents” - provides information about conducting workshop classes with a group of parents. The second part - "Workshop on counseling work with parents" contains a set of useful tools (exercises) to be used by counselors in practices. The third part is for parents' self-study.

The training is supposed to enable acquiring new practical skills by parents. Theoretical knowledge will be limited to the necessary minimum. Practical skills will be developed during interactive workshops (role playing, psychological exercises, dramas etc.). Theoretical knowledge will be given to the participants of the training as a part of auxiliary materials. Auxiliary materials, available on Cd-Rom will be enriched by multimedia.

\section{Summary}

Vocational guidance and vocational counselling are able to make full use of the advantages of the Information and Communication Technologies. So professionals of this field together with parents and children can be clearly benefited from its use. The project initial report showed that both groups are ready to make use of ICT as a complement for face-to-face lessons, and are willing to take advantage of its flexibility and possibilities. The communication and learning platform created in the project, as a tool to use with parents for non-formal education is also available.

\section{References}

[1] AAVV. Parents as career counsellors of their children. Training for parents. Anna Paszkowska-Rogacz (Ed). Warsaw. 2009.

[2] Parents Project Official Website: http://www.parentsproject.eu/ [06/10/2009].

[3] Parents Project Virtual Environment: http://parents.cesga.es/ [06/10/2009]. 